\title{
Not-Quite-Great Depressions of Turkey: A Quantitative Analysis of Economic Growth over 1968 - 2004*
}

\author{
Deniz Çiçek ${ }^{\dagger}$ and Ceyhun Elgin ${ }^{\ddagger}$ \\ Department of Economics, University of Minnesota (UMN)
}

February 10, 2009

\begin{abstract}
:
Following the great depressions methodology suggested by Cole and Ohanian (1999) and Kehoe and Prescott $(2002,2007)$, we use growth accounting and standard dynamic general equilibrium models to study growth performance of Turkey from 1968 to 2004. We find that the primary source of output growth in Turkey was growth in total factor productivity, rather than growth in labor and capital inputs. Among the various specifications of dynamic general equilibrium models employed, the one with capital adjustment costs and variable taxes comes closest to account for the data. This suggests that rigidities affecting capital accumulation and distortionary taxes have a crucial role in explaining the evolution of the Turkish economy.
\end{abstract}

Keywords: growth accounting, total factor productivity, great depressions, Turkey, dynamic general equilibrium

JEL Classification Numbers: E32, N14, O40

*Elgin acknowledges financial support from the Graduate Research Partnership Program Fellowship by the CLA at the University of Minnesota.

${ }^{\dagger}$ University of Minnesota, Department of Economics, 4-101 Hanson Hall Room, 1925 4th Street S., Minneapolis, MN 55455, USA, e-mail: cicek002@umn.edu.

${ }^{\ddagger}$ University of Minnesota, Department of Economics, 4-101 Hanson Hall Room, 1925 4th Street S., Minneapolis, MN 55455, USA, e-mail: elgin@umn.edu. 


\section{Introduction}

Dynamic general equilibrium growth models are widely used in modern economics for studying most macroeconomic phenomena, including economic growth, business cycles, and monetary and fiscal policies. Recently, Cole and Ohanian (1999) and Kehoe and Prescott (2002, 2007) opened the way to use them for analyzing economic depressions as well as less severe downturns. In this paper, we follow the great depressions methodology developed in these papers to study growth performance of Turkey for the period 1968-2004.

The great depression methodology has been so far applied to several economies. Among these contributions, the most notable ones include Hayashi and Prescott (2002) for Japan; Beaudry and Portier (2002) for France; Bergoeing et al. (2002) for Mexico and Chile; Kehoe (2003) for Argentina; Conesa and Kehoe (2003) for Spain; Kehoe and Ruhl (2003) for New Zealand and Switzerland; and Conesa, Kehoe and Ruhl (2007) for Finland. The applied dynamic general equilibrium models used in most of these papers involve aggregate production functions that treat total factor productivity as external to the agents, but not as invariant to the policy. Only few papers, such as Conesa, Kehoe and Ruhl (2007), attempt at endogenizing the TFP, with little success though.

To the best of our knowledge, this is the first paper that follows the great depressions methodology to study the Turkish economy. In this study, we inspect growth trends of the Turkish economy and use growth accounting to evaluate the contributions of total factor productivity (TFP), total hours worked, and capital to the output growth. Then, we conduct experiments on calibrated growth models and compare the variables generated by these models with the actual data.

Throughout our period of analysis (1968-2004), the Turkish economy went through two major periods of stagnation. The first one is the deep recession in the period 1977-1984. Being quite severe and persistent, this downturn almost, but not precisely, satisfies the definition of great depression suggested by Kehoe and Prescott $(2002,2007)$. The other period of stagnation, 1991-2001, considerably differs from the former. Within this period, the Turkish economy experienced episodes of considerably high rates of growth. However, 
these episodes were followed by severe recessions in the years 1994, 1999, and 2001, which contributed the dismal record of $0.65 \%$ average growth of real GDP per-capita over the period 1991-2001. Indeed, despite the rapid growth in the period 1984-1990, even the entire period 1977-2001 comes close to satisfying Kehoe and Prescott's (2002, 2007) definition of great depression. Since neither period exactly satisfies the conditions for a great depression, as also Conesa, Kehoe and Ruhl (2007) does for the Japanese and the Finnish recessions, we call these periods as "not-quite-great" depressions of Turkey.

Our findings from the growth accounting exercise indicate that TFP is the most crucial determinant in the evolution of the output per-capita. That is, as TFP grows, the output grows as well; and as TFP stagnates, so does the output. The capital-output ratio also contributes positively to the growth of output per capita from 1968 to 2004. The increase in the capital-output ratio is significant, especially in periods where TFP stagnates; e.g., the periods 1977 - 1983 and 1991 - 2001. As for hours of work, the general trend of hours per capita is decreasing. Therefore, its contribution to growth in output per-capita is negative, except in the period $1991-2001$.

Our benchmark model, absent of distortionary taxes and capital adjustment costs, closely predicts the evolution of output per capita. However, it does not perform well in predicting the path of capital-output ratio and hours worked per capita. Even though adding taxes and adjustment costs one at a time improves the results upon the benchmark case, the simulation with both capital adjustment costs and taxes performs best. This suggests that rigidities affecting capital accumulation and distortionary taxes have a crucial role in explaining the evolution of the Turkish economy.

The paper is organized as follows: In the next section, we document the growth performance of the Turkish economy and conduct a growth accounting exercise. In section 3, we present the theoretical framework of our analysis. In the first subsection of this section, we introduce a standard one-sector dynamic general equilibrium growth model as the benchmark model of this paper. In the following subsections, we extend this model by incorporating capital adjustment costs and taxes, both separately and jointly. In section 4, we 
perform numerical experiments to evaluate the performance of the different specifications of the model to account for the data. Finally, we conclude.

\section{Evolution of the Turkish Economy}

In this section, we will first inspect the evolution of GDP per capita in Turkey through the lenses of the great depression literature. Following that, we will perform a growth accounting exercise to identify the sources of growth.

\subsection{Inspecting the GDP data}

Figure 1 illustrates the evolution of GDP-per capita in Turkey from 1950 up to 2007 together with different trends. The average growth rate of GDP per capita in this period was approximately 2.75\%. Figure 1 also shows that the growth performance of Turkey should be evaluated in at least two subperiods. A visual inspection of the figure reveals that something changes after 1976. The average growth rate of Turkey from 1950 up to 1976 was $3.43 \%$, whereas it was only $1.28 \%$ from 1977 up to 2001 . This number goes up to $2.1 \%$ if one extends the endpoint of the latter interval up to 2007.

Figure 2 compares the actual performance of the economy with trends of $2 \%, 2.75 \%$, and $3.43 \%$ constant growth rates applied after 1976. Again, notice that $3.43 \%$ was the average growth rate from 1950 up to 1976 and 2.75\% was the average growth rate between 1950 and 2007. We also use the $2 \%$ trend growth rate, which is the choice of Kehoe and Prescott (2002, 2007) for the analysis.

Following the figure 2, figure 3 plots the detrended GDP per capita series using these different trends. The choice of the relevant trend growth rate deserves some discussion because it will determine the depths of recessions and/or depressions in our analysis of the Turkish economy. Kehoe and Prescott $(2002,2007)$ argue that one should use the $2 \%$ percent trend growth rate, which is approximately the average growth rate of USA throughout the 20th century. On the other hand, Cole and Ohanian (1999) use the average growth rate 
of USA between 1919 and 1997, excluding the depression years and come up with 1.9\%. Similarly, Beaudry and Portier (2002) use 2.98\% France, which is the average growth rate of GDP per capita in France throughout the 20th century, excluding the depression years between 1930 and 1939. The choice of the relevant trend rate for Turkey will not only determine the depths of the recessions but also whether we can name several periods in Turkey as a great depression or not

Kehoe and Prescott $(2002,2007)$ define a great depression as follows: An economy is in a great depression in the time period $T=\left[T_{1}, T_{2}\right]$, if it satisfies three conditions: ${ }^{1}$

1. There exists some $t \in T$, s.t. $\frac{y_{t}}{g^{t-T_{1}} y_{T_{1}}}-1 \leq-0.20$

2. There exists some $t \leq T_{1}+10$, s.t. $\frac{y_{t}}{g^{t-T_{1}} y_{T_{1}}}-1 \leq-0.15$

3. There are no $T_{1}$ and $T_{2}$ in $\mathrm{T}$, such that $T_{2} \geq T_{1}+10$, and $\frac{y_{T_{2}}}{g^{T_{2}-T_{1}} y_{T_{1}}}-1 \geq 0$

where $y_{t}=Y_{t} / N_{t}$ for any $t$, and $g$ is the relevant trend growth rate which is chosen to be equal to 1.02 by Kehoe and Prescott (2002, 2007).

Given this definition, if we take $g$ to be equal to 1.02 , a visual inspection of figure 3 reveals that the period from 1977 to 1984 satisfy the second and the third criteria, but not the first one, because the GDP per capita does not fall up to $20 \%$, but only to $15 \%$ below trend. But, if we take $g$ to be equal to 1.0275 or 1.0343 , things change. One can see from figure 3 that all the criteria of the definition are now satisfied in both cases.

One can also suspect whether there are any other periods which might be considered as a great depression. The answer is not quite yes. The only year, where it comes close to satisfy the definition, is in 2001, where the GDP per capita falls to almost $20 \%$ below trend, even with respect to the conservative choice of a trend rate of $2 \%$. But that downturn of the economy was not sustained and the economy started to grow at higher rates after 2002.

\footnotetext{
${ }^{1}$ The original version of the paper (Kehoe and Prescott (2002)) only requires the first two of the three conditions here.
} 


\subsection{Growth Accounting}

To evaluate the contributions of different factors to the changes in output per capita, we set up an accounting framework based on the neoclassical growth model.

We use the standard Cobb-Douglas production function, which is of the form:

$$
Y_{t}=A_{t} K_{t}^{\alpha} H_{t}^{1-\alpha}
$$

where $Y_{t}$ is the output at the end of year $t, K_{t}$ is the quantity of capital stock, $H_{t}$ is the total hours worked, and $A_{t}$ is the TFP.

We calculate TFP by the following equation:

$$
A_{t}=\frac{Y_{t}}{K_{t}^{\alpha} H_{t}^{1-\alpha}}
$$

We, then, compile data on output, total hours worked and investment from national accounts. $^{2}$

To create the capital stock series we simply employ the the perpetual inventory method using the following system of equations:

$$
\begin{aligned}
& K_{t+1}=K_{t}(1-\delta)+I_{t} \\
& \frac{K_{1950}}{Y_{1950}}=\frac{1}{10} \sum_{t=1951}^{1960} \frac{K_{t}}{Y_{t}}
\end{aligned}
$$

Equation (3) is the standard law of motion for capital. Equation (4) is based on the assumption that the capital-output ratio of the initial period should match the average capital-output ratio over some reference period. Here, we choose the capital stock so that the capital-output ratio in 1950 matches its average over 1951 - 1960.

Equation (3) and (4) make system of 38 unknowns $\left(K_{1968}, K_{1969}, \ldots . . K_{2004}\right.$ and $\left.\delta\right)$ and 37 equations. We will use another equation, to make $\delta$ consistent with the average ratio of

\footnotetext{
${ }^{2}$ The sources of data are discussed in the appendix.
} 
depreciation to GDP observed in the data over the data period used for calibration purposes. Unfortunately, consumption of fixed capital series for Turkey is only available after 1977. So then we find for Turkey that the ratio of depreciation to GDP over the period 1977 - 2004 is

$$
\frac{1}{28} \sum_{t=1977}^{2004} \frac{\delta K_{t}}{Y_{t}}=0.0648
$$

The three equations above yield now enough information to calibrate $\delta$ and create the capital stock series for the period of interest. The calibrated value for $\delta$ is equal to $4.7 \%$. To our knowledge there is no study on Turkey which calibrates $\delta$, though there are some empirical studies using different values for it. For example, $\delta$ is assumed to be equal to $4.2 \%$ per annum in Altug, Filiztekin and Pamuk (2008) and 5\% in Ismihan and Metin-Ozcan(2006)

The production function, when written in per capita terms, becomes

$$
y_{t}=A_{t} k_{t}^{\alpha} h_{t}^{1-\alpha}
$$

where lower case letters denote per capita variables. Taking the natural logarithm of equation (6) and manipulating it yields:

$$
\log \left(y_{t}\right)=\log \left(h_{t}\right)+\frac{\alpha}{1-\alpha} \log \left(\frac{k_{t}}{y_{t}}\right)+\frac{1}{1-\alpha} \log \left(A_{t}\right)
$$

Equation (7) allows us to decompose growth in output per capita in three factors ${ }^{3}$ : Changes in TFP, changes in the capital-output ratio and changed in hours of work per capita. Of course, in an economy which is on a balanced growth path, one would expect that changes in output per capita are largely, if not all, explained by changes in TFP.

$\log \left(\frac{y_{t+1}}{y_{t}}\right)=\frac{1}{1-\alpha}\left\{\log \left(A_{t+1}\right)-\log \left(A_{t}\right)\right\}+\frac{\alpha}{1-\alpha}\left\{\log \left(k_{t+1} / y_{t+1}\right)-\log \left(k_{t} / y_{t}\right)\right\}+\log \left(h_{t+1}\right)-\log \left(h_{t}\right)$

\footnotetext{
${ }^{3}$ Throughout the growth accounting exercise and the simulations of the model we will assume that $\alpha=0.35$. In their empirical paper, Ismihan and Metin-Ozcan (2006) suggest that $\alpha$ of the Turkish economy lies between 0.35 and 0.50 . We use different values in this range and report only results with $\alpha=0.35$.
} 
The result of this growth accounting exercise is graphically presented in figure 4 and the numerical results can be checked in column 3 of table 1 . Both the table and the figure confirm our premise, that TFP is the main determinant of economic growth in Turkey. The sign of TFP growth also determines the sign of the growth in per capita output, except the period 1991 - 2001. In this period, following the capital account liberalization in 1989 and ensuring the full convertibility of the Turkish Lira in 1990, even tough TFP is decreasing, the increase in the capital-output ratio makes the average growth rate in per capita output positive. As for hours of work, the general trend of hours per capita is decreasing. Therefore, its contribution to growth in output per-capita is negative, except in the period $1991-2001$.

\section{The Dynamic General Equilibrium Model}

In this section, we present the theoretical framework of our analysis. First, we introduce the benchmark model. Next, we extend the model by introducing capital adjustment costs and taxes, each separately. Finally, we discuss the complete model both with capital adjustment costs and taxes.

\subsection{The Benchmark Model}

We use the dynamic general equilibrium model in Conesa, Kehoe and Ruhl (2007) as the base model. The model involves an infinitely-lived representative household and a representative firm, both making decisions in perfectly competitive markets. The household's instantaneous utility function, $U$, the firm's production technology, $F$, and the sequence of TFP, $A_{t}$, are exogenous elements of the model.

Taking the wage rate, $w_{t}$, and the rental rate of capital, $r_{t}$, for each period $t=0,1, .$. as given, the representative household chooses paths of consumption $\left\{C_{t}\right\}_{t=0}^{\infty}$, working hours $\left\{H_{t}\right\}_{t=0}^{\infty}$, and capital $\left\{K_{t+1}\right\}_{t=0}^{\infty}$ to maximize her life-time utility

$$
\sum_{t=0}^{\infty} \beta^{t}\left[\gamma \log \left(C_{t}\right)+(1-\gamma) \log \left(\bar{h} N_{t}-H_{t}\right)\right]
$$


subject to

$$
\begin{array}{r}
C_{t}+K_{t+1}=w_{t} H_{t}+\left(1+r_{t}-\delta\right) K_{t}, \\
C_{t}, K_{t}, I_{t} \geq 0, \\
0 \leq H_{t} \leq \bar{h} N_{t}, \\
K_{0} \text { given, }
\end{array}
$$

where $I_{t}=K_{t+1}-(1-\delta) K_{t}$ is investment; $\beta, \beta \in(0,1)$, is the discount factor; $\gamma, \gamma \in(0,1)$, is the consumption share; $\delta, \delta \in(0,1)$, is the depreciation rate of capital; $\bar{h}$ is the number of hours available to each person for market work and $\bar{h} N_{t}$ is the aggregate number of hours available for work.

Equations (10)-(13) are, respectively, the budget constraint, the non-negativity constraints, the time constraint on hours worked and the constraint on the initial capital.

The production technology is given by the equation (1). Taking the prices $w_{t}$ and $r_{t}$ as given, the representative firm solves the cost minimization problem. The first order conditions, together with the zero-profit condition due to perfect competition, imply the following optimality conditions:

$$
\begin{gathered}
w_{t}=(1-\alpha) A_{t} K_{t}^{\alpha} H_{t}^{-\alpha} \\
r_{t}=\alpha A_{t} K_{t}^{\alpha-1} H_{t}^{1-\alpha} .
\end{gathered}
$$

Finally, the feasibility condition is given by

$$
C_{t}+K_{t+1}-(1-\delta) K_{t}=A_{t} K_{t}^{\alpha} H_{t}^{1-\alpha}
$$

Definition: Given the sequences of TFP, $\left\{A_{t}\right\}_{t=0}^{\infty}$, and population, $\left\{N_{t}\right\}_{t=0}^{\infty}$, and the initial capital stock, $K_{0}$; a competitive equilibrium is a sequence of prices, $\left\{w_{t}, r_{t}\right\}_{t=0}^{\infty}$, and allocations, $\left\{C_{t}, H_{t}, K_{t+1}\right\}_{t=0}^{\infty}$, such that

(1) Given the prices, allocations solve the household's problem, 
(2) Allocations satisfy the firm's optimality conditions (14)-(15),

(3) Allocations satisfy the feasibility condition (16).

Next, we will obtain a system of equations that characterizes the equilibrium of the model. First, we derive the first-order conditions from the households utility maximization problem,

$$
\begin{gathered}
w_{t}\left(\bar{h} N_{t}-H_{t}\right)=\left[\frac{1-\gamma}{\gamma}\right] C_{t} \\
\frac{C_{t+1}}{C_{t}}=\beta\left(1-\delta+r_{t+1}\right) .
\end{gathered}
$$

Then, we insert the prices from the the firm optimality conditions (14) and (15) into the household optimality conditions, (17) and (18). Thus, including the feasibility condition (16), we obtain the following system of equations that characterizes the equilibrium:

$$
\begin{array}{r}
(1-\alpha) A_{t} K_{t}^{\alpha} H_{t}^{-\alpha}\left(\bar{h} N_{t}-H_{t}\right)=\left[\frac{1-\gamma}{\gamma}\right] C_{t} \\
\frac{C_{t+1}}{C_{t}}=\beta\left(1-\delta+\alpha A_{t+1} K_{t+1}^{\alpha-1} H_{t+1}^{1-\alpha}\right) \\
C_{t}+K_{t+1}-(1-\delta) K_{t}=A_{t} K_{t}^{\alpha} H_{t}^{1-\alpha}
\end{array}
$$

Given the initial condition $K_{0}$, an equilibrium of this model satisfies this system of equations and the following transversality condition:

$$
\lim _{t \rightarrow \infty} \beta^{t} \gamma \frac{K_{t+1}}{C_{t}}=0
$$

In section 4, we will use the equations (19)-(21) to carry out our numerical simulations.

\subsection{Adding adjustment costs to capital accumulation}

In this section, we introduce a simple friction into capital accumulation process. As in Lucas and Prescott (1971) and Kehoe (2003), we assume there are constant returns to scale 
adjustment costs to capital stock:

$$
K_{t+1}=(1-\delta) K_{t}+\phi\left(I_{t} / K_{t}\right) K_{t}
$$

where

$$
\phi\left(I_{t} / K_{t}\right)=\left[\delta^{1-\eta}\left(I_{t} / K_{t}\right)^{\eta}+(\eta-1) \delta\right] / \eta .
$$

Notice that the case where $\eta=1$ corresponds to the base model with no adjustment costs. Following Kehoe (2003), we will assume $\eta=0.9$ throughout the analysis.

Clearly, this extension only changes the resource constraint of the previous subsection and everything else remains unchanged.

\subsection{Adding taxes}

In this section, we follow Conesa, Kehoe and Ruhl (2007) and introduce distortionary taxes into the benchmark model. We assume the government levies proportional taxes on consumption, labor income and capital income and uses the proceed to finance transfers. The household budget constraint (10) in the base model is replaced by

$$
\left(1+\tau_{C t}\right) C_{t}+K_{t+1}=\left(1-\tau_{H t}\right) w_{t} H_{t}+\left(1+\left(1-\tau_{K t}\right)\left(r_{t}-\delta\right)\right) K_{t}+T_{t} .
$$

where $\tau_{C t}$ is the tax rate on consumption, $\tau_{H t}$ is the tax rate on labor income, $\tau_{K t}$ is the tax rate on capital income, and $T_{t}$ is a lump-sum transfer.

Again, the household maximizes her life-time utility function subject to the budget constraint, the non-negativity constraints, the time constraint, and the initial condition for capital stock, $K_{0}$.

The firm's problem is the same as the base problem. Thus, the firm optimality conditions (14) and (15) in the base model are valid in this specification, as well. Since tax revenues are lump-sum rebated back to consumers, the resource constraint is still given by (16). 
Finally, the government budget constraints is given by

$$
\left.T_{t}=\tau_{C t} C_{t}+\tau_{K t}\left(r_{t}-\delta\right)\right) K_{t}+\tau_{H t} w_{t} H_{t}
$$

Definition: Given the sequences of TFP, $\left\{A_{t}\right\}_{t=0}^{\infty}$, population, $\left\{N_{t}\right\}_{t=0}^{\infty}$, tax policies $\left\{\tau_{C t}, \tau_{K t}, \tau_{H t}\right\}_{t=0}^{\infty}$, and the initial capital stock, $K_{0}$; a tax distorted competitive equilibrium is a sequence of prices, $\left\{w_{t}, r_{t}\right\}_{t=0}^{\infty}$, allocations, $\left\{C_{t}, H_{t}, K_{t+1}\right\}_{t=0}^{\infty}$, and transfers $\left\{T_{t}\right\}_{t=0}^{\infty}$ such that

(1) Given the prices, allocations solve the household's problem,

(2) Allocations satisfy the firm's optimality conditions (14) and (15),

(3) Allocations, tax policies and transfers satisfy the government budget constraint (26),

(4) Allocations satisfy the feasibility condition (16).

\subsection{Complete Model}

Our complete model uses both capital adjustment costs and distortionary taxes. Since we have already defined the equilibrium with and without taxes above, we omit the definition for this case. We refer the reader to Conesa, Kehoe, and Ruhl (2007) for a detailed discussion on solving models of this type. ${ }^{4}$

\section{$4 \quad$ Numerical Experiments}

In this section, we first show how we calibrate the remaining parameters of the model, $\beta$ and $\gamma$ and then discuss the simulations of different versions of the model. Lastly, we compare those with the actual data.

\subsection{Calibration}

The calibration procedure is explained in more detail in Conesa, Kehoe and Ruhl (2007). The idea is that as we defined in the previous section, the model features a stand-in household

\footnotetext{
${ }^{4}$ Accompanying documentation can also be accessed online at www.greatdepressionsbook.com.
} 
that chooses paths of leisure, investment and consumption to maximize his/her utility. The paths of population and TFP are exogenously given, and the household has perfect foresight over their values. We start the model at date 0 , i.e. $T=1968$ and let time run out to infinity.

Next, $\beta$, and $\gamma$ are calibrated. In the benchmark model this is done using,

$$
\begin{gathered}
\beta=\frac{C_{t+1}}{C_{t}\left(1-\delta+\alpha Y_{t+1} / K_{t+1}\right)} \\
\gamma=\frac{C_{t} H_{t}}{Y_{t}\left(\bar{h} N_{t}-H_{t}\right)(1-\alpha)+C_{t} H_{t}}
\end{gathered}
$$

Moreover, the TFP, which is exogenously given to the stand-in household is calculated using the growth accounting equation derived above.

For the cases with taxes $\beta$ and $\gamma$ are calibrated using,

$$
\begin{gathered}
\beta=\frac{\left(1+\tau_{C_{t+1}}\right) C_{t+1}}{C_{t}\left(1+\tau_{C_{t}}\right)} \frac{1}{1+\left(1-\tau_{k_{t+1}}\right)\left(r_{t+1}-\delta\right)} \\
\gamma=\frac{\left(1+\tau_{C_{t}}\right) C_{t} H_{t}}{\left(1-\tau_{l_{t}}\right) Y_{t}\left(\bar{h} N_{t}-H_{t}\right)(1-\alpha)+C_{t} H_{t}}
\end{gathered}
$$

Also the TFP is calculated using

$$
A_{t}=\frac{C_{t}+X_{t}}{K_{t}^{1-\alpha} H_{t}^{\alpha}}
$$

where $C_{t}+X_{t}$ is the real GDP at factor prices in the data.However, the contribution of TFP to growth is reported using

$$
\hat{A}_{t}=\frac{\hat{Y}_{t}}{K_{t}^{1-\alpha} H_{t}^{\alpha}}
$$

where 


$$
\hat{Y}_{t}=\left(1+\tau_{C_{t}}\right) C_{t}+X_{t}
$$

is the real GDP at market prices of the base year $\bar{T}=2000$

Also notice that, the exogenous sequence population is the one measured from the data in the growth accounting exercise. Following Conesa, Kehoe and Ruhl (2007), we assign a value of $\bar{h}=100$ for an individual's time endowment of hours available for market work per week.

The information above is enough to simulate the benchmark model without taxes. For the model with taxes, see the data appendix for calculation of the tax rates.

\subsection{Simulation Results}

Figures 5 to 10 compare the models predictions with the data. Similarly, last three columns of tables 1 and 2, perform the growth accounting exercise to the series generated by different versions of the model.

In total, we run 6 simulations. Three of them ignore capital adjustment costs. The results of these simulations are reported in table 1 and figures 5, 6, and 7. The remaining three simulations assume that there are capital adjustment costs. The results of these simulations are reported in table 2 and figures 8, 9, and 10. In each of these 2 categories of simulatins, we run the model first without any taxes, then with constant taxes, denoted by tax 1 and lastly with actual taxes, denoted by tax $2 .{ }^{5}$

First observation we make from the figures is that the model with constant taxes (with or without capital adjustment costs) improves very little upon the benchmark case. Figures 6 and 9 reveal that both models largely underestimate the capital-output ratio, especially after 1980. Similarly, from figures 7 and 10 we observe that both overestimate the hours worked per capita, again especially after 1980. All models predict similar results with respect to the output per capita.

\footnotetext{
${ }^{5}$ The calculation of the tax rates for the Turkish economy was a daunting task and needs a discussion more than the scope of this subsection. Therefore, we relegate this discussion to the appendix.
} 
Next, we observe that, for its performance to predict the capital output ration and hours worked per capita, the model with varying taxes considerably improves upon the benchmark and the case with constant taxes. This observations is true both in the case with and without adjustment costs, even tough the model both with adjustment costs and varying taxes comes closes to account for the data. One can also confirm this result, by comparing the last column of table 2 with the data, which is the third column of table 2. Numbers considerably come closer to the data under last column. The only period where none of the models perform well is the period between 1991 and 2001. Considering the high degree of turbulence of the economy in this period, this shouldn't be a surprising result.

\section{Conclusion}

In this paper, we use growth accounting and a standard dynamic general equilibrium model to study the growth performance of Turkey between 1968 and 2004. Using the well established great depressions methodology, we find that the primary source of output growth in Turkey was growth in total factor productivity, rather than growth in labor and capital inputs. Among the various specifications of dynamic general equilibrium models employed, the one with capital adjustment costs and variable taxes comes closest to account for the data. This suggests that rigidities affecting capital accumulation and distortionary taxes have a crucial role in explaining the evolution of the Turkish economy. The result also provides an evidence that the models based on the evolution of TFP alone are generally inadequate for understanding economic growth and recessions. Indeed, our paper highlights the importance of recognizing the role of tax policies and rigidities in capital accumulation. We believe that those are fertile areas for further research on the Turkish economy. 


\section{References}

Altug, S., Filiztekin,A., Pamuk, S.Sources of long-term economic growth for Turkey, 18802005 European Review of Economic History, 12(3), pp 393-430, December 2008.

Beaudry, P. and Portier,F. 2002, The French Depression in the 1930s, Review of Economic Dynamics, 5, 73-99.

Bergoeing, R. Kehoe, P.J., Kehoe, T.J, and Soto, R. 2002, A Decade Lost and Found: Mexico and Chile in the 1980s, Review of Economic Dynamics, 5, 166-205.

Carey, D. Tchilinguirian, H. 2000, Average Effective Tax Rates on Capital, Labour and Consumption, OECD Economics Department Working Papers 258.

Cole, H. L. and Ohanian, L.E. 1999, The Great Depression in the United States from a Neoclassical Perspective, Federal Reserve Bank of Minneapolis Quarterly Review, 23, 2-24.

Conesa, J. C. and Kehoe, T.J. 2003, Productivity, Taxes, and Hours Worked in Spain 19752000, University of Minnesota working paper.

Conesa, J.C., Kehoe, T.J., Ruhl,K.J. 2007, Modeling Great Depressions: The Depression in Finland in the 1990s, Federal Reserve Bank of Minneapolis Quarterly Review, 31:1, 1644.

Cicek, D. Elgin, C. 2009. Business Cycle Accounting for Turkey: 1968 - 2004, working paper.

Gurgel, A., Metcalf, G.E., Osouf,N., Reilly,J. 2007. Computing Tax Rates for Economic Modeling: A Global Dataset Approach MIT Joint Program on the Science and Policy of Global Change Technical Note.

Ismihan, M. Metin-Ozcan,K. 2006. Sources of Growth in the Turkish Economy, 1960-2004. Iktisat Isletme ve Finans, 241. 74-86.

Kehoe, T.J. 2003, What Can We Learn from the Current Crisis in Argentina? Scottish Journal of Political Economy, 50, 60933. 
Kehoe, T.J., and Ruhl, K.J., 2003, Recent Great Depressions: Aggregate Growth in New Zealand and Switzerland 19732000, New Zealand Economic Papers, 37, 540.

Kehoe, T. J. and Prescott, E.C. 2002, Great Depressions of the Twentieth Century., Review of Economic Dynamics,5, 1-18.

Kehoe, T. J. and Prescott, E.C. editors. 2007, Great Depressions of the Twentieth Century. Federal Reserve Bank of Minneapolis.

Lucas, R. E. and Prescott, E.C. 1971, Investment Under Uncertainty, Econometrica, 39, 659-681.

Mendoza, E. G., Razin,A. and Tesar,L.L. 1994, Effective Tax Rates in Macro- economics: Cross-Country Estimates of Tax Rates on Factor Incomes and Consumption, Journal of Monetary Economics, 34(3), 297-323. 


\section{A Appendix}

\section{A.1 Data}

Data for GDP, population, investment are taken from the national accounts data of the State Planning Organization which is available at http://www.dpt.gov.tr, and for hours of work data we used the Conference Board and Groningen Growth and Development Centre's Total Economy Database. The Total Economy Database is available at www.conferenceboard.org/economics

The data on consumption of fixed capital which we use to calculate the depreciation to GDP ratio is from national accounts data at www.sourceoecd.org

For tax exercises in this framework Conesa, Kehoe and Ruhl (2007) describe a very simple procedure to obtain consumption, capital and labor tax series from OECD country tables. Their model is a little different then the methodology suggested by Mendoza, Razin and Tsar (1994). ${ }^{6}$ Even tough, Turkey is also an OECD member, revenue statistics for Turkey is far from being complete. Also, even tough there are some studies (such as Gurgel et. al. (2007), and Carey and Tchilinguirian (2000)) estimating capital, labor and consumption taxes for Turkey for one or two specific years, to our knowledge there aren't any long terms tax series available for Turkey.

To overcome this problem, we do the following:

First, following Conesa, Kehoe and Ruhl (2007), we create a series of $\tau_{C t}$ by using the following formula

$$
\tau_{C t}=\frac{R_{\text {con }, t}}{C_{t}-R_{\text {con }, t}}
$$

where $R_{c o n, t}$ is simply the revenue from general taxes on goods and services plus excise taxes which is available at the Turkish Revenue Administration website ${ }^{7}$ and $C_{t}$ is simply consumption of households and nonprofit institutions serving households available through

\footnotetext{
${ }^{6}$ See the corresponding papers for discussion.

${ }^{7}$ www.gib.gov.tr
} 
national accounts. For the capital and labor taxes, we simply use the generated $\tau_{H t}$ and $\tau_{K t}$ series by Cicek and Elgin (2009). Then, we do two analysis with taxes, one taking the average of taxes over the period (1968 - 2004) and running the model with constant taxes. This case is denoted in tables 1 and 2 by tax 1 . The second exercise, instead uses the actual series that we have generated and is denoted in tables 1 and 2 by tax 2 . 


\section{A.2 Tables and Figures}

Table 1: The model without adjustment costs Decomposition of average annual changes in real output per capita $(\%)$

\begin{tabular}{|c|c|c|c|c|c|}
\hline Period & & Data & Base Case & Model: Tax 1 & Model: Tax 2 \\
\hline \multirow[t]{4}{*}{ 1968-2004 } & change in $\mathrm{Y} / \mathrm{N}$ & 2.15 & 1.86 & 1.76 & 1.86 \\
\hline & due to TFP & 1.76 & 1.76 & 1.77 & 1.76 \\
\hline & due to $\mathrm{K} / \mathrm{Y}$ & 1.1 & 0.16 & 0.06 & 0.48 \\
\hline & due to $\mathrm{H} / \mathrm{N}$ & -0.72 & -0.05 & -0.07 & -0.38 \\
\hline \multirow[t]{4}{*}{$1968-76$} & change in $\mathrm{Y} / \mathrm{N}$ & 3.5 & 4.42 & 4.24 & 3.88 \\
\hline & due to TFP & 3.7 & 3.7 & 3.66 & 3.63 \\
\hline & due to $\mathrm{K} / \mathrm{Y}$ & 1.04 & 0.37 & 0.24 & 0.34 \\
\hline & due to $\mathrm{H} / \mathrm{N}$ & -1.24 & 0.34 & 0.34 & -0.09 \\
\hline \multirow[t]{4}{*}{$1977-83$} & change in $\mathrm{Y} / \mathrm{N}$ & -0.4 & -2.15 & -2.16 & -0.74 \\
\hline & due to TFP & -1.93 & -1.93 & -1.76 & -1.84 \\
\hline & due to $K / Y$ & 2.89 & 1.38 & 1.13 & 2.72 \\
\hline & due to $\mathrm{H} / \mathrm{N}$ & -1.35 & -1.6 & -1.53 & -1.62 \\
\hline \multirow[t]{4}{*}{$1984-90$} & change in $\mathrm{Y} / \mathrm{N}$ & 3.48 & 4.35 & 4.33 & 3.85 \\
\hline & due to TFP & 4.07 & 4.07 & 3.95 & 4.01 \\
\hline & due to $K / Y$ & 0.19 & -0.82 & -0.66 & -0.12 \\
\hline & due to $\mathrm{H} / \mathrm{N}$ & -0.78 & 1.1 & 1.05 & -0.04 \\
\hline \multirow[t]{4}{*}{ 1991-2001 } & change in $\mathrm{Y} / \mathrm{N}$ & 0.65 & -1.28 & -1.3 & -1.54 \\
\hline & due to TFP & -1.43 & -1.43 & -1.2 & -1.18 \\
\hline & due to $\mathrm{K} / \mathrm{Y}$ & 1.78 & 1.83 & 1.72 & 1.66 \\
\hline & due to $\mathrm{H} / \mathrm{N}$ & 0.3 & -1.68 & -1.82 & -2.02 \\
\hline \multirow[t]{4}{*}{$2002-04$} & change in $\mathrm{Y} / \mathrm{N}$ & 6.4 & 9.29 & 8.7 & 9.7 \\
\hline & due to TFP & 10.88 & 10.88 & 10.14 & 10.04 \\
\hline & due to $\mathrm{K} / \mathrm{Y}$ & -3.28 & -7.22 & -7.35 & -7.2 \\
\hline & due to $\mathrm{H} / \mathrm{N}$ & -1.2 & 5.63 & 5.91 & 6.86 \\
\hline
\end{tabular}


Table 2: The Model with adjustment costs

Decomposition of average annual changes in real output per capita (\%)

\begin{tabular}{|c|c|c|c|c|c|}
\hline Period & & Data & $\begin{array}{c}\text { Model: } \\
\text { Adjustment Costs }\end{array}$ & $\begin{array}{c}\text { Model: Adj. Cost } \\
\text { and tax } 1\end{array}$ & $\begin{array}{c}\text { Model: Adj. Costs } \\
\text { and tax } 2\end{array}$ \\
\hline \multirow[t]{4}{*}{$1968-2004$} & change in $\mathrm{Y} / \mathrm{N}$ & 2.15 & 1.53 & 1.69 & 2.03 \\
\hline & due to TFP & 1.44 & 1.44 & 1.97 & 1.93 \\
\hline & due to $\mathrm{K} / \mathrm{Y}$ & 1.42 & 0.15 & 0.05 & 0.49 \\
\hline & due to $\mathrm{H} / \mathrm{N}$ & -0.7 & -0.06 & -0.33 & -0.39 \\
\hline \multirow[t]{4}{*}{$1968-76$} & change in $\mathrm{Y} / \mathrm{N}$ & 3.5 & 4.39 & 4.5 & 4.09 \\
\hline & due to TFP & 3.66 & 3.66 & 3.92 & 3.89 \\
\hline & due to $\mathrm{K} / \mathrm{Y}$ & 1.07 & 0.33 & 0.24 & 0.31 \\
\hline & due to $\mathrm{H} / \mathrm{N}$ & -1.19 & 0.4 & 0.34 & -0.11 \\
\hline \multirow[t]{4}{*}{$1977-83$} & change in $\mathrm{Y} / \mathrm{N}$ & -0.4 & -2.53 & -1.9 & -0.44 \\
\hline & due to TFP & -2.19 & -2.19 & -1.54 & -1.63 \\
\hline & due to $\mathrm{K} / \mathrm{Y}$ & 3.13 & 1.43 & 1.18 & 2.75 \\
\hline & due to $\mathrm{H} / \mathrm{N}$ & -1.35 & -1.77 & -1.53 & -1.57 \\
\hline \multirow[t]{4}{*}{$1984-90$} & change in $\mathrm{Y} / \mathrm{N}$ & 3.48 & 4.1 & 4.47 & 3.99 \\
\hline & due to TFP & 3.68 & 3.68 & 4.1 & 4.16 \\
\hline & due to $\mathrm{K} / \mathrm{Y}$ & 0.58 & -0.77 & -0.67 & -0.11 \\
\hline & due to $\mathrm{H} / \mathrm{N}$ & -0.78 & 1.19 & 1.04 & -0.06 \\
\hline \multirow[t]{4}{*}{ 1991-2001 } & change in $\mathrm{Y} / \mathrm{N}$ & 0.65 & -1.96 & -1.34 & -1.39 \\
\hline & due to TFP & -1.95 & -1.95 & -1.05 & -1.06 \\
\hline & due to $\mathrm{K} / \mathrm{Y}$ & 2.3 & 1.94 & 1.71 & 1.66 \\
\hline & due to $\mathrm{H} / \mathrm{N}$ & 0.29 & -1.95 & -2.01 & -2.00 \\
\hline \multirow[t]{4}{*}{ 2002-04 } & change in $\mathrm{Y} / \mathrm{N}$ & 6.4 & 9.17 & 6.27 & 9.62 \\
\hline & due to TFP & 10.42 & 10.42 & 10.44 & 10.08 \\
\hline & due to $\mathrm{K} / \mathrm{Y}$ & -2.82 & -7.78 & -7.54 & -7.15 \\
\hline & due to $\mathrm{H} / \mathrm{N}$ & -1.2 & 6.53 & 3.37 & 6.68 \\
\hline
\end{tabular}


Figure 1. Real GDP per person in Turkey, 1950-2007

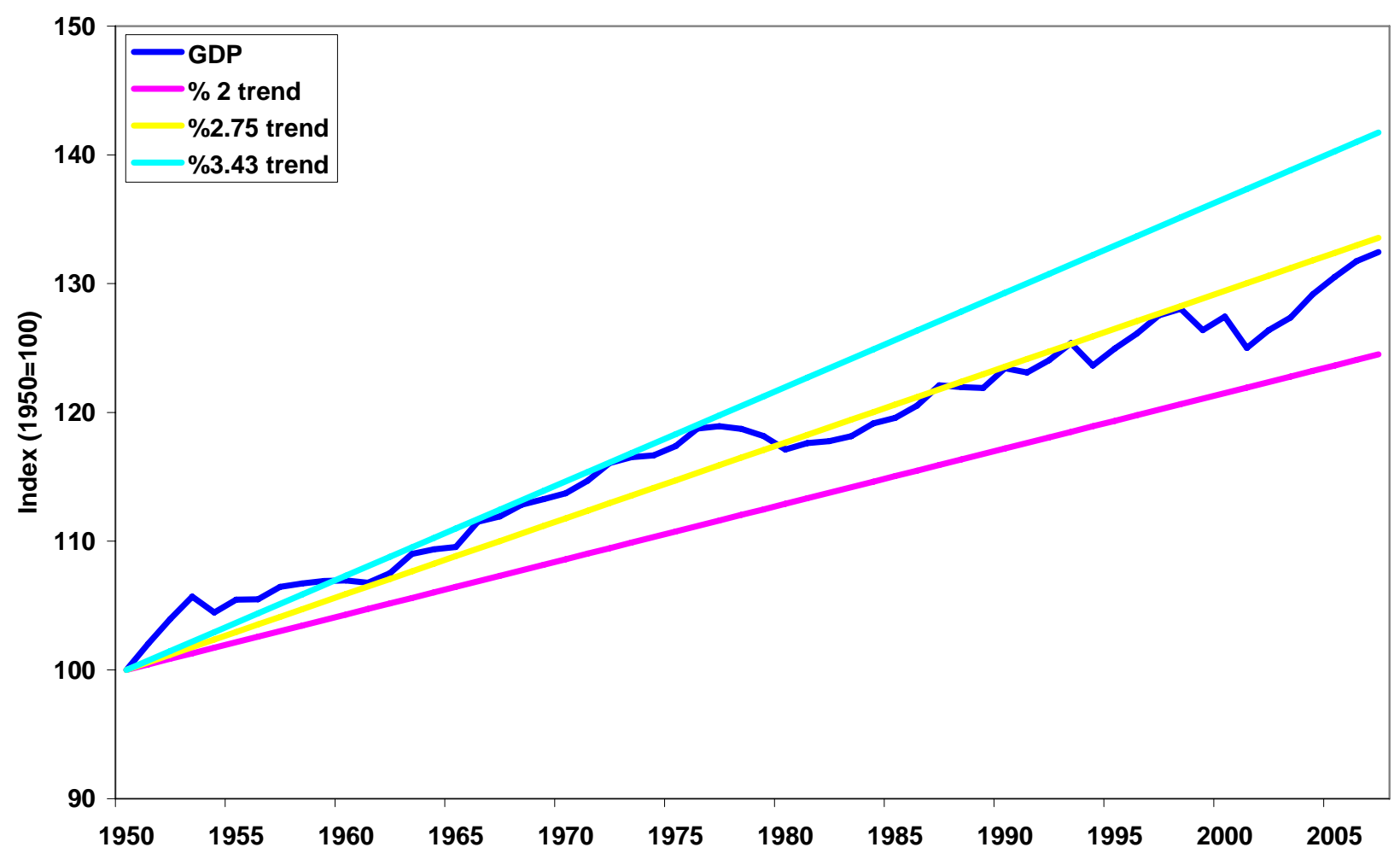

Figure 2. Real GDP per person in Turkey, 1976-2007

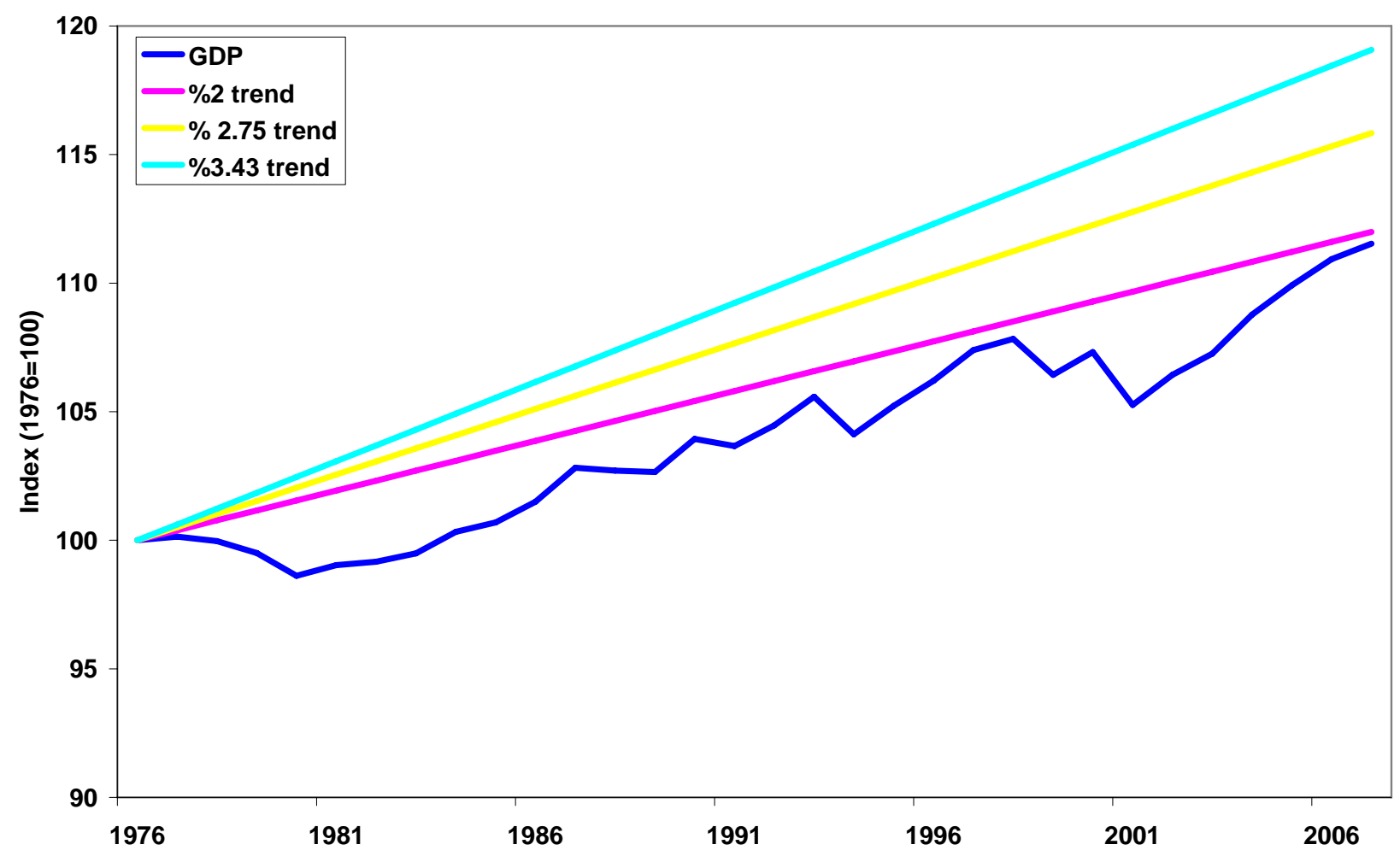


Figure 3. Detrended GDP: 1976-2007

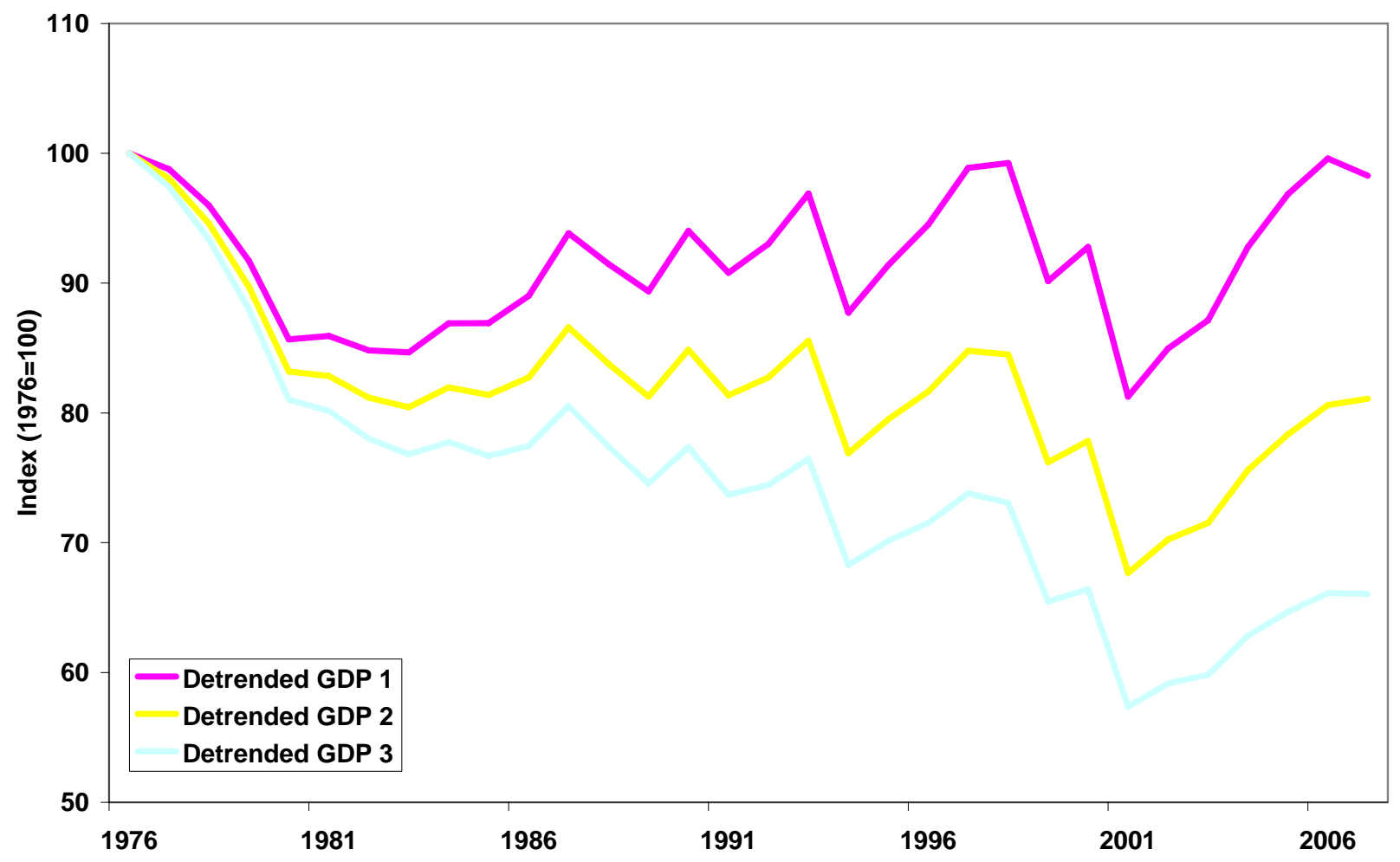

Figure 4. Growth Accounting

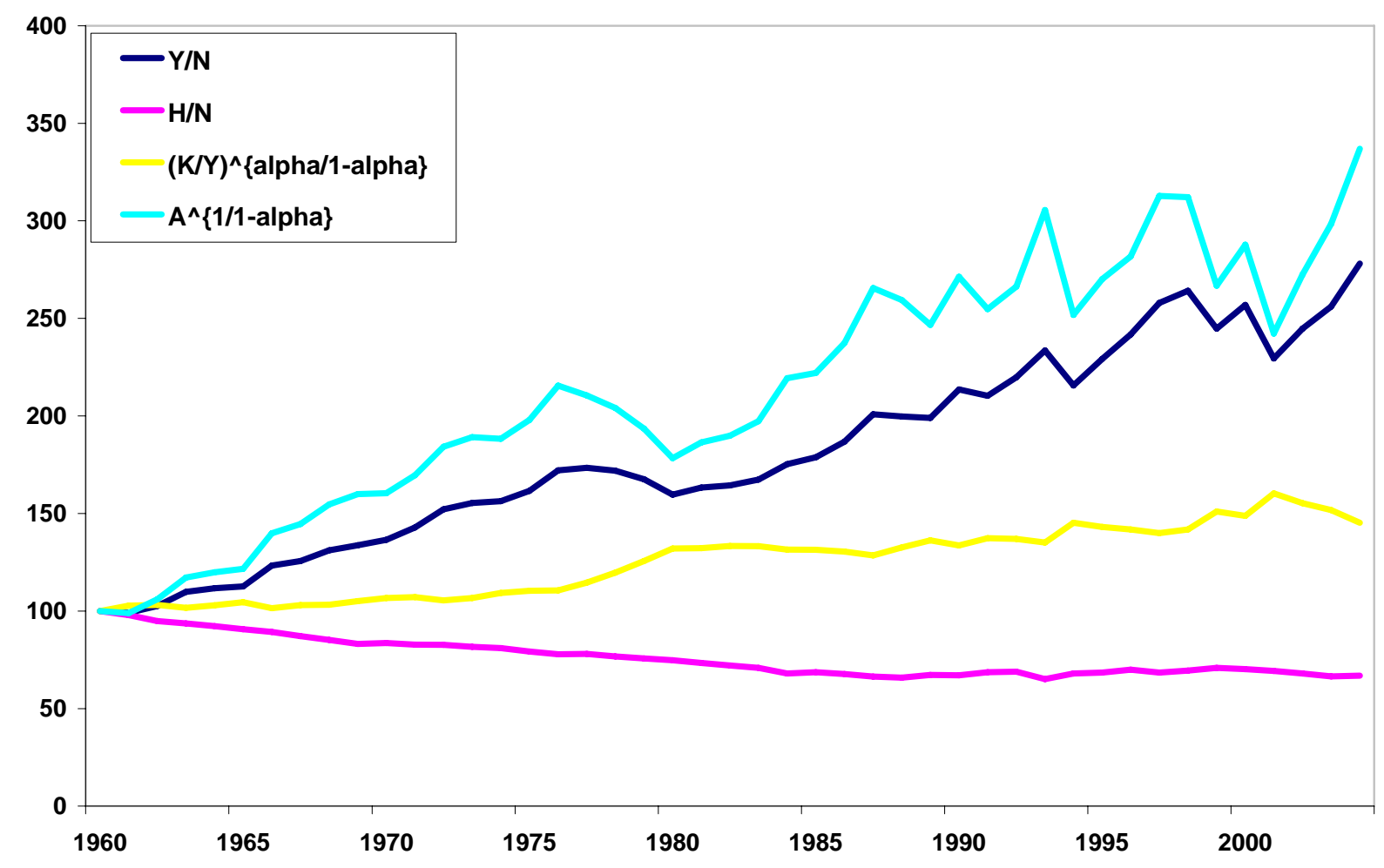


Figure 5. Detrended real GDP per person in Turkey: Data, base model, model with tax 1 and $\operatorname{tax} 2$

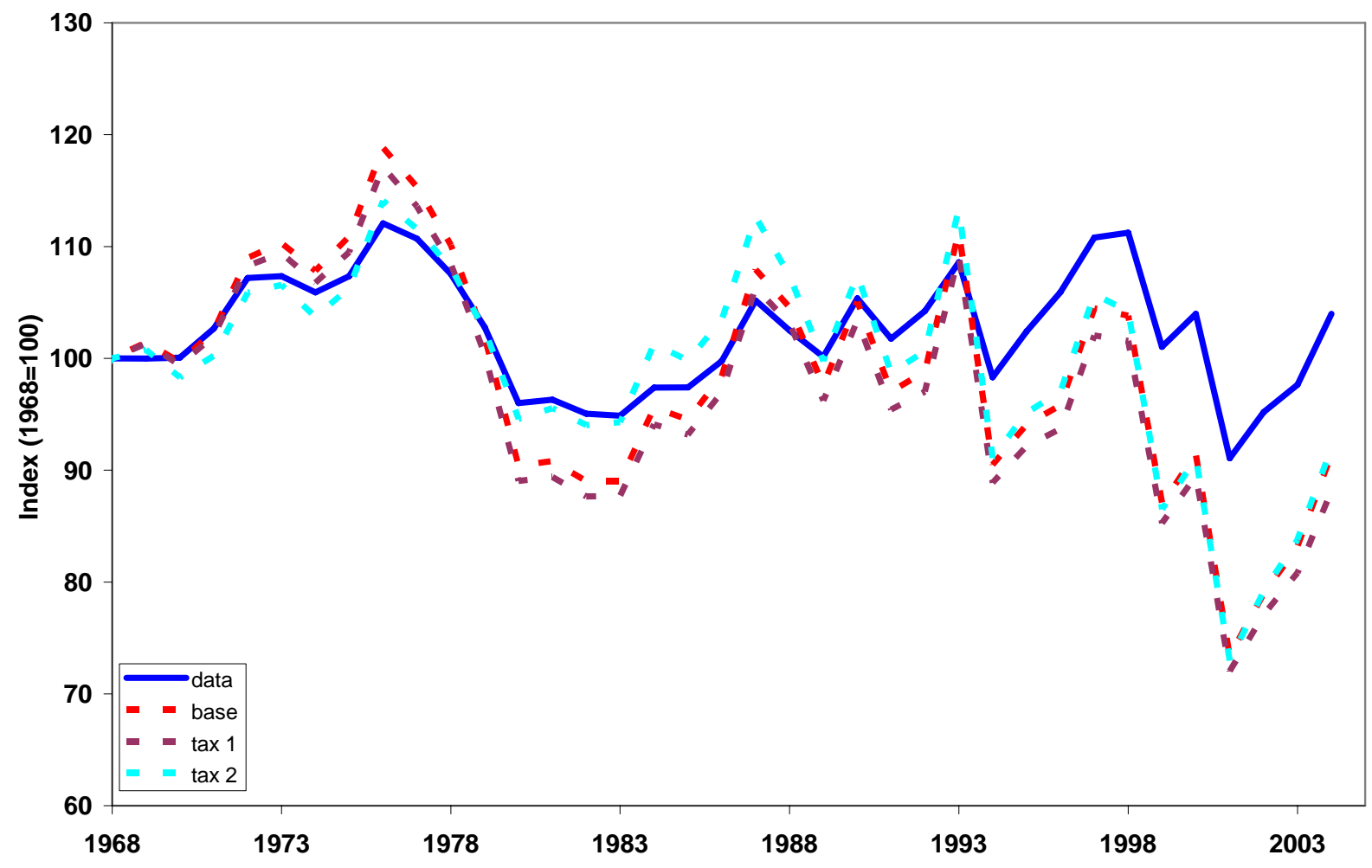

Figure 6. Capital/output ratio in Turkey: Data, base model, model with tax 1 and tax 2

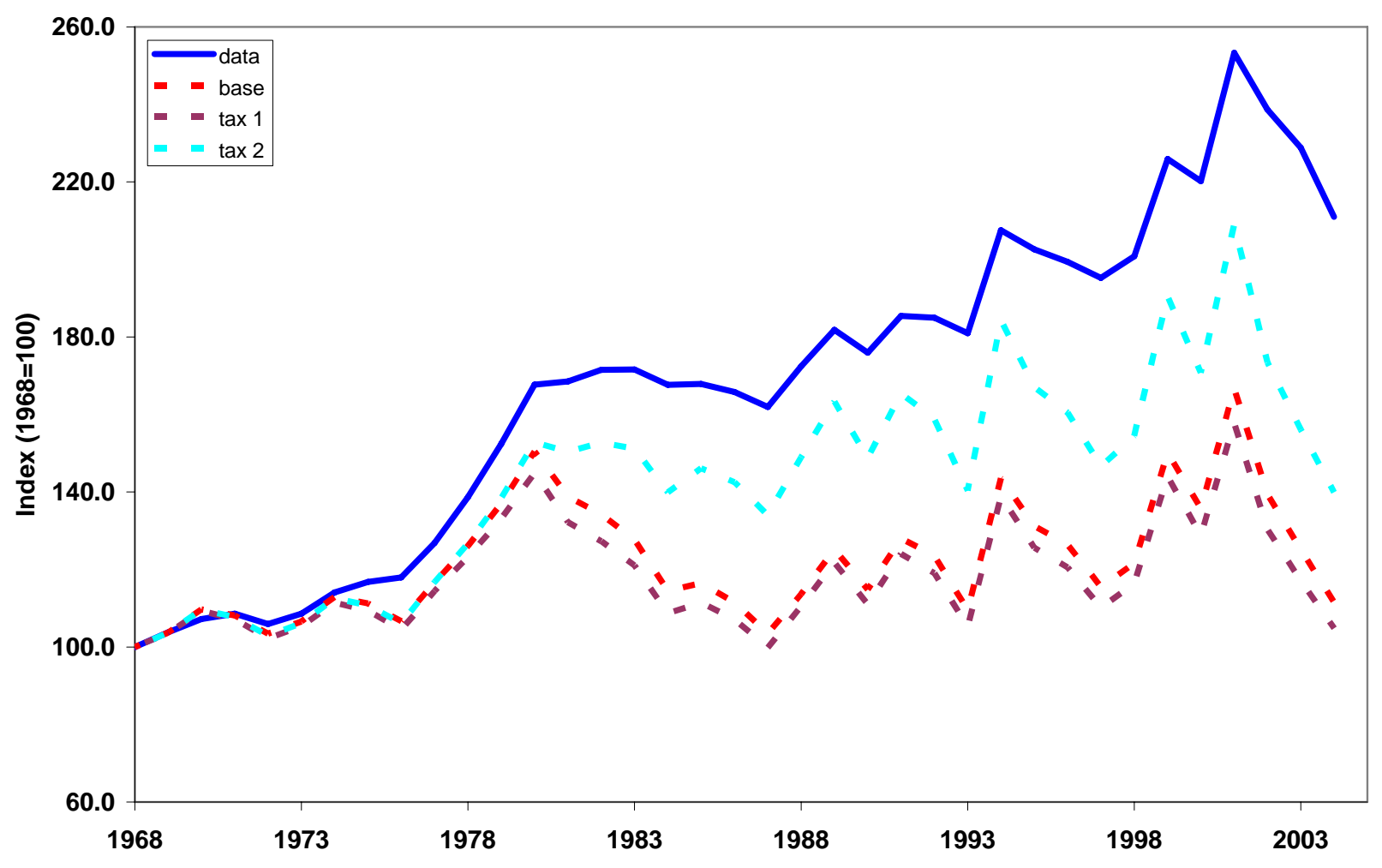


Figure 7. Hours worked per person in Turkey: Data, base model, model with tax 1 and tax2

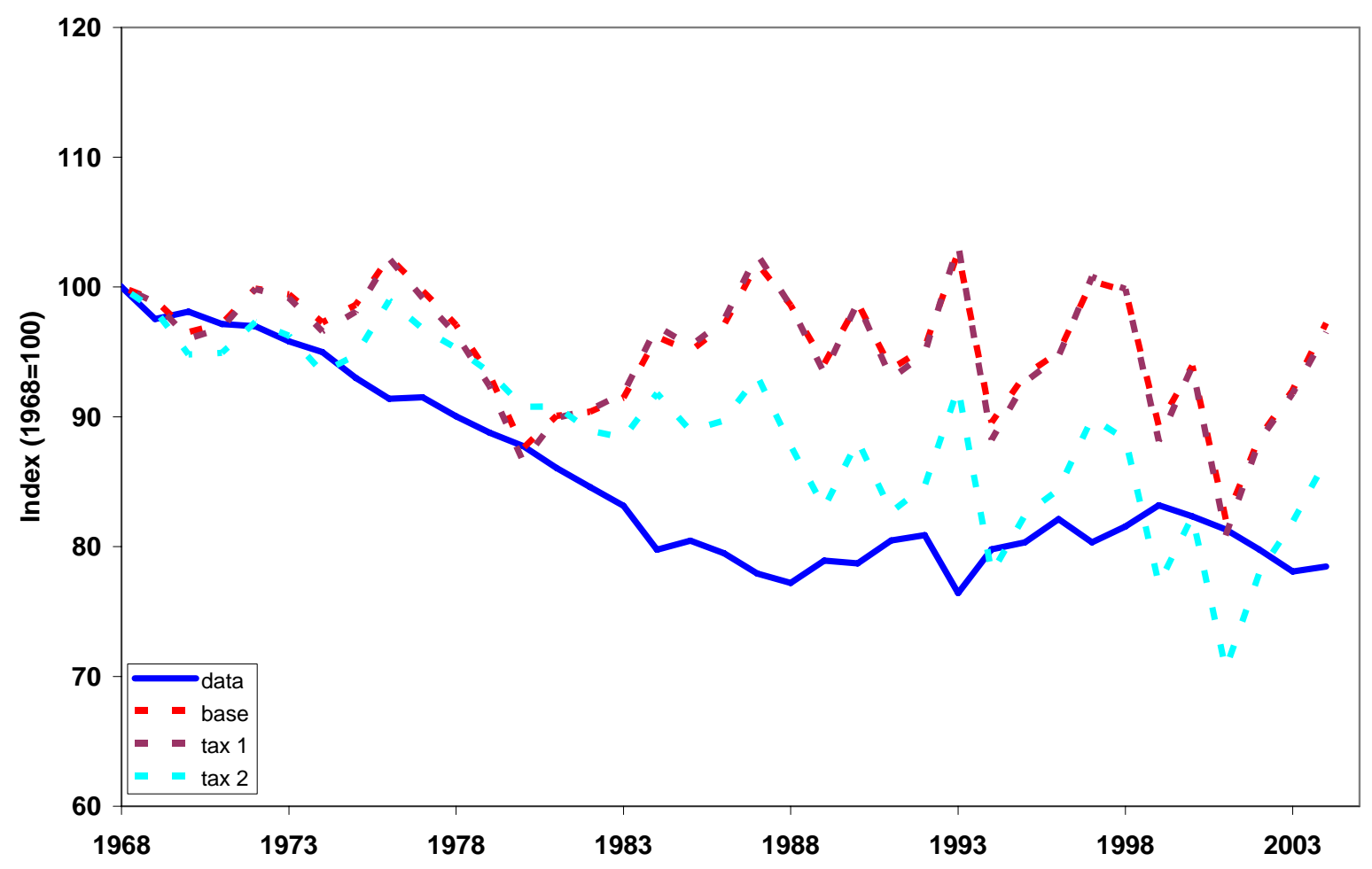

Figure 8. Detrended real GDP per person in Turkey: Data, base model, model with tax 1 and tax 2 (with adjustment costs)

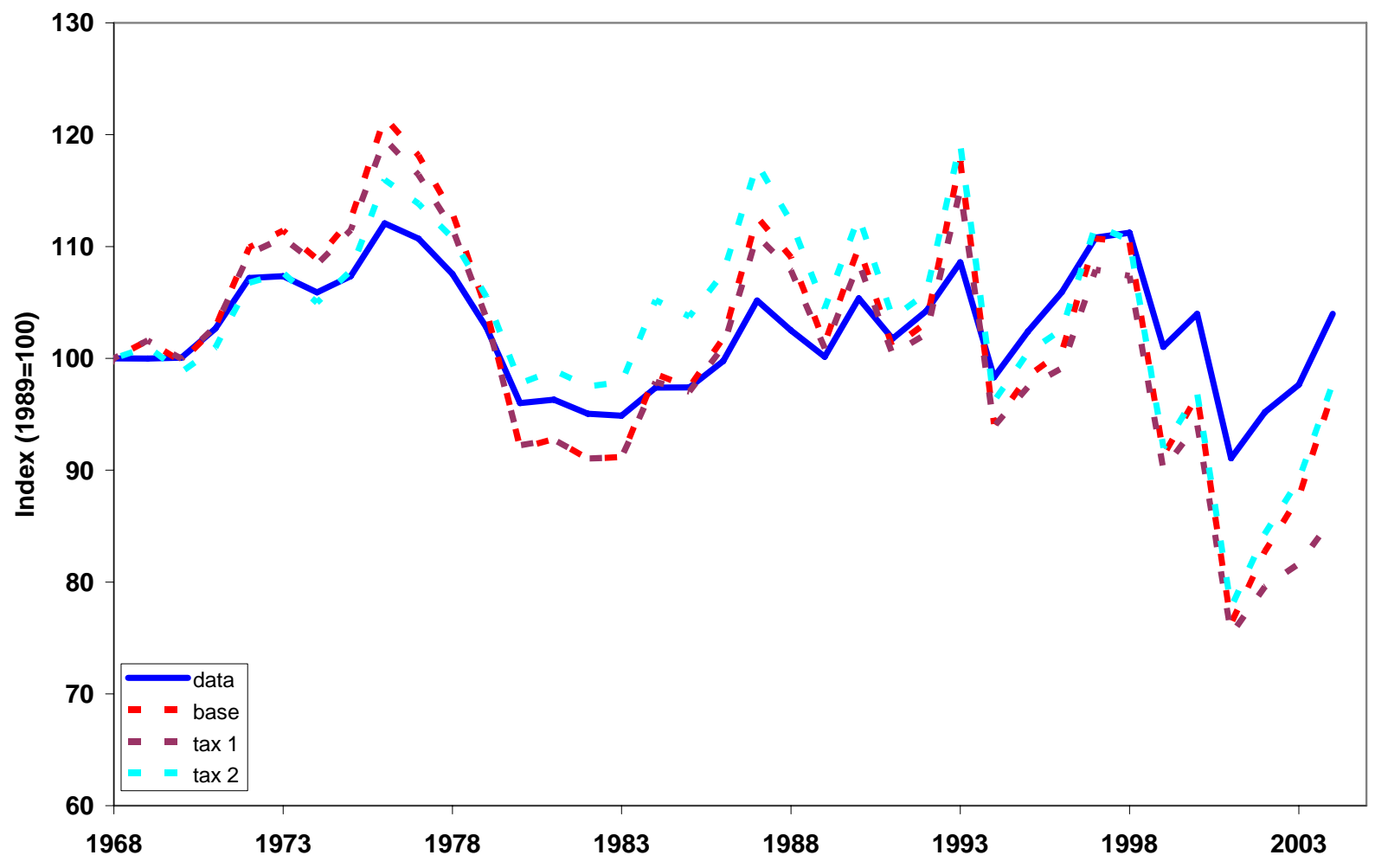


Figure 9. Capital/output ratio in Turkey: Data, base model, model with tax 1 and tax 2 (with adjustment costs)

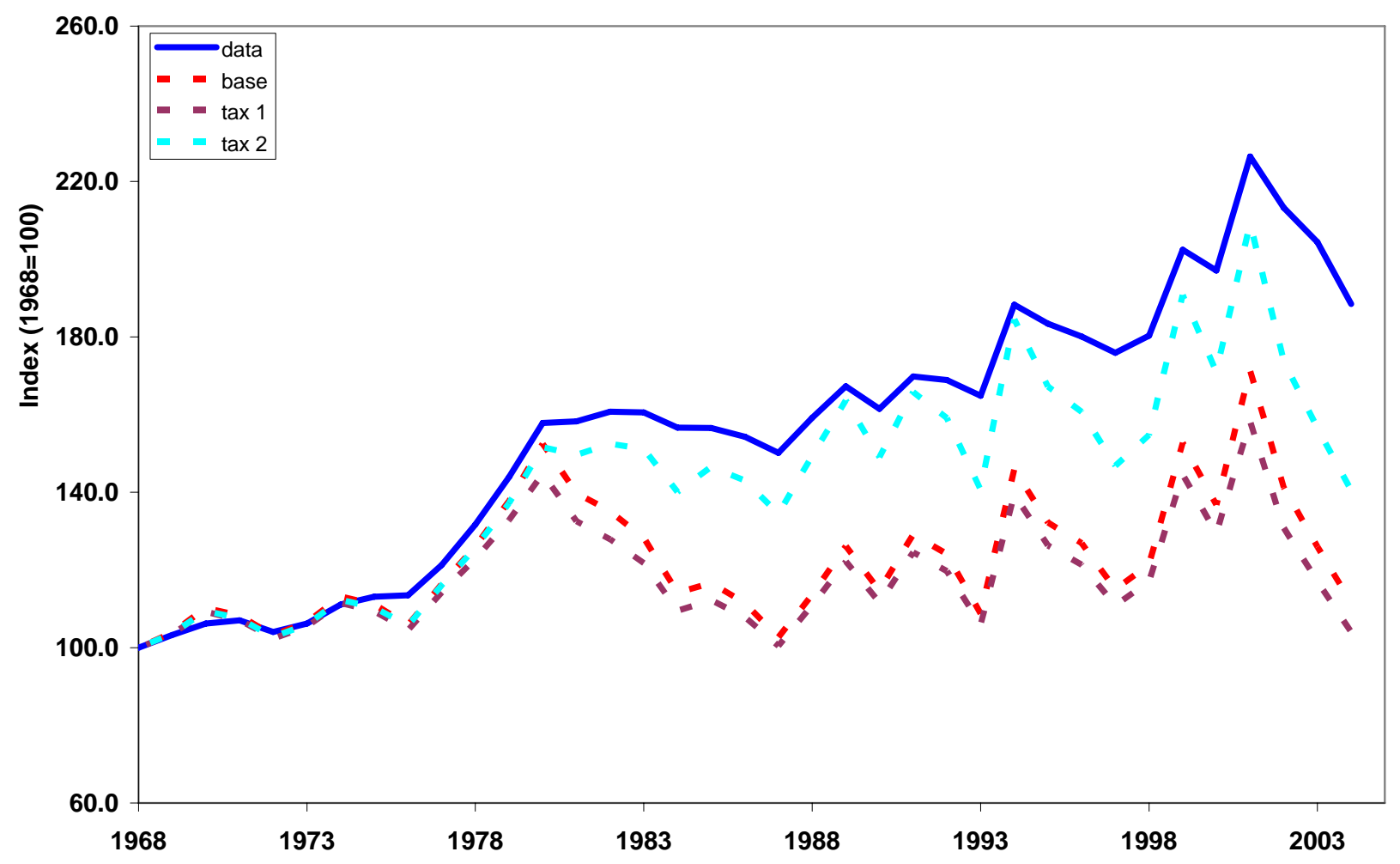

Figure 10. Hours worked per person in Turkey: Data, base model, model with tax 1 and tax 2 (with adjustment costs)

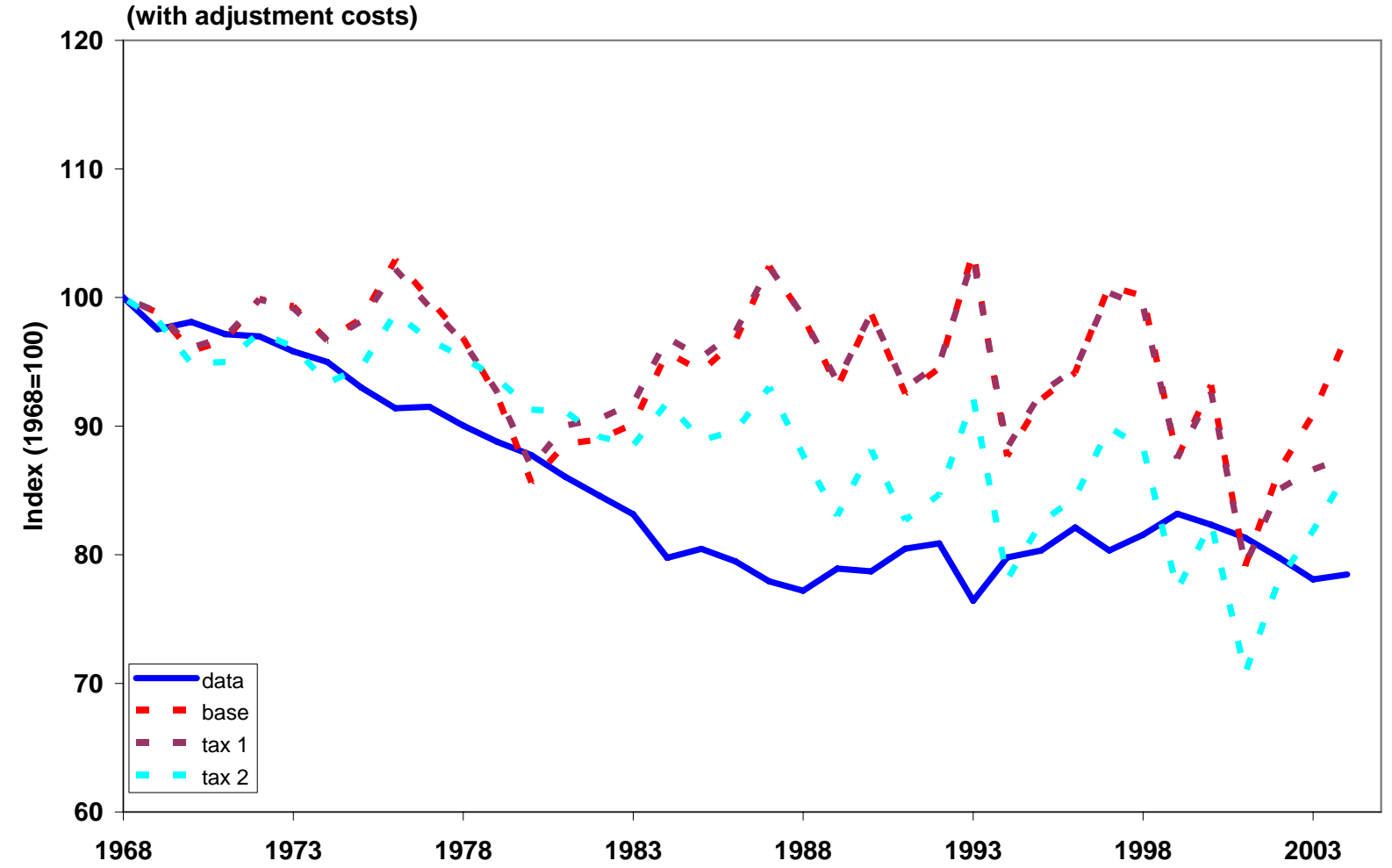

